\title{
SOCIOECONOMIC DETERMINANTS OF INFANT MORTALITY RATE IN ASEAN: A PANEL DATA ANALYSIS
}

\author{
Vita Kartika Sari ${ }^{1 *}$, Dwi Prasetyani \\ ${ }^{1,2}$ Department of Economics Development, Faculty of Economics and Business, \\ Sebelas Maret University, Indonesia \\ ${ }^{1}$ vitahanifanaira@gmail.com; ${ }^{2}$ nd_prasetyani@yahoo.com
}

Received: $03^{\text {rd }}$ April 2021/ Revised: $11^{\text {th }}$ July $2021 /$ Accepted: $12^{\text {th }}$ July 2021

How to Cite: Sari, V. K. \& Prasetyani, D. (2021). Socioeconomic determinants of infant mortality rate in ASEAN: A panel data analysis. Journal of ASEAN Studies, 9(1), 73-85, https://doi.org/10.21512/jas.v9i1.7280

\begin{abstract}
The infant mortality rate indicates the health status of a country. Previous studies have proven that socioeconomic factors have a significant influence on infant mortality rates in both developed and developing countries. Further studies on infant mortality rates are useful for public service strategic policy in the health sector. The main purpose of this study was to analyze the socioeconomic factors influencing infant mortality rates in ASEAN based on panel data estimates for 2000-2017. The dependent variable for this study was infant mortality rate, while the independent variables were health expenditure, female labor force, maternal fertility rate, and GDP per capita. The authors concluded that the main cause of infant mortality in ASEAN is care during delivery. Other influencing factors include family health status, maternal education level, and socio-economic inequality. This study found that the size of the female workforce has a strong influence on increasing the infant mortality rate in ASEAN. The fertility rate also had a strong influence on increasing infant mortality rate in ASEAN, while GDP per capita had a negative influence on infant mortality rate. Health expenditure is proven to have no effect on the increase of infant mortality rates in ASEAN.
\end{abstract}

Keywords: infant mortality rate, socioeconomic factors, ASEAN

\section{INTRODUCTION}

The infant mortality rate is one of the main health indicators (see: Arik and Arik, 2009; Dallolio, et al., 2012; Naveed, et al., 2011; Rosicova, et al., 2011). The issue of infant mortality rate has long been a special topic of study by researchers, especially in developing countries (Gomez, Hanna, and Oliva, 2012; Hanmer, Lensink, and White, 2003; Oloo, 2005), because the infant mortality rate is related to other socioeconomic factors, as well as being an 
indicator of human welfare. Bhatia, et al, (2018) also stated that efforts to reduce infant mortality rates are a top priority in developing countries. In addition, there is also an interesting discussion on whether prosperity level is related to health status. The infant mortality rate tends to be high in poor countries and low in developed countries (Chaudhuri \& Mandal, 2020; Klugman, et al, 2019; Ullah, et al, 2011). Developed countries focus on providing healthcare in the form of quality care, including access to quality maternal and child health services. Sustainable development must consider the socioeconomic factors. Economists agree that economic development is not only measured by GDP per capita growth or other macroeconomic indicators, but also supported by public health status (Hanmer, Lensink, and White, 2003). This is in line with the policies of the United Nations Development Program (UNDP) and the World Health Organization (WHO) on the importance of human development in terms of health, education, poverty, and the environment as stated in the Human Development Index to achieve the Sustainable Development Goals (SDGs) (Bhatia, et.al, 2018).

According to WHO (2020), the infant mortality rate is defined as the death of a child before one year of age over a certain period of time. Lamichhane, et al. (2017) emphasized the infant mortality rate as a primary human development indicator and a key part of the challenge to provide good quality health so as to realize social welfare. Previous studies by Dallolio, et al., (2012); Erdogan, Ener, and Arica, (2013); Genowska, et al. (2015); and Iram and Butt (2008) explained the influence of socioeconomic factors on infant mortality rates. The economic factors were national income, income per capita, health expenditure, unemployment rates, and income equalization, while the social factors were the education level of the mother, nutrition, environmental factors such as pollution, healthcare quality, and women's welfare. Iram and Butt (2008) found the main influencing factors of infant mortality rates in Pakistan were environmental factors, family income, and the education level of the mother. Lamichhane, et al (2017) identified several influencing key factors of the infant mortality rate in Nepal, including birth spacing, breastfeeding, parenting styles, and ecology. In line with this, Sarkar, Dhar, and Rouhoma (2018) also found differences in the adequate number of health facilities in developed countries compared with the relative lack in developing countries, and identified several determining factors of infant mortality rates, namely delivery assistance, the education level of the mother, and total population. Most ASEAN countries are developing countries, and the infant mortality rate is still rarely studied in the ASEAN region, so it is interesting to estimate the influence of socioeconomic factors on infant mortality rate in ASEAN. 


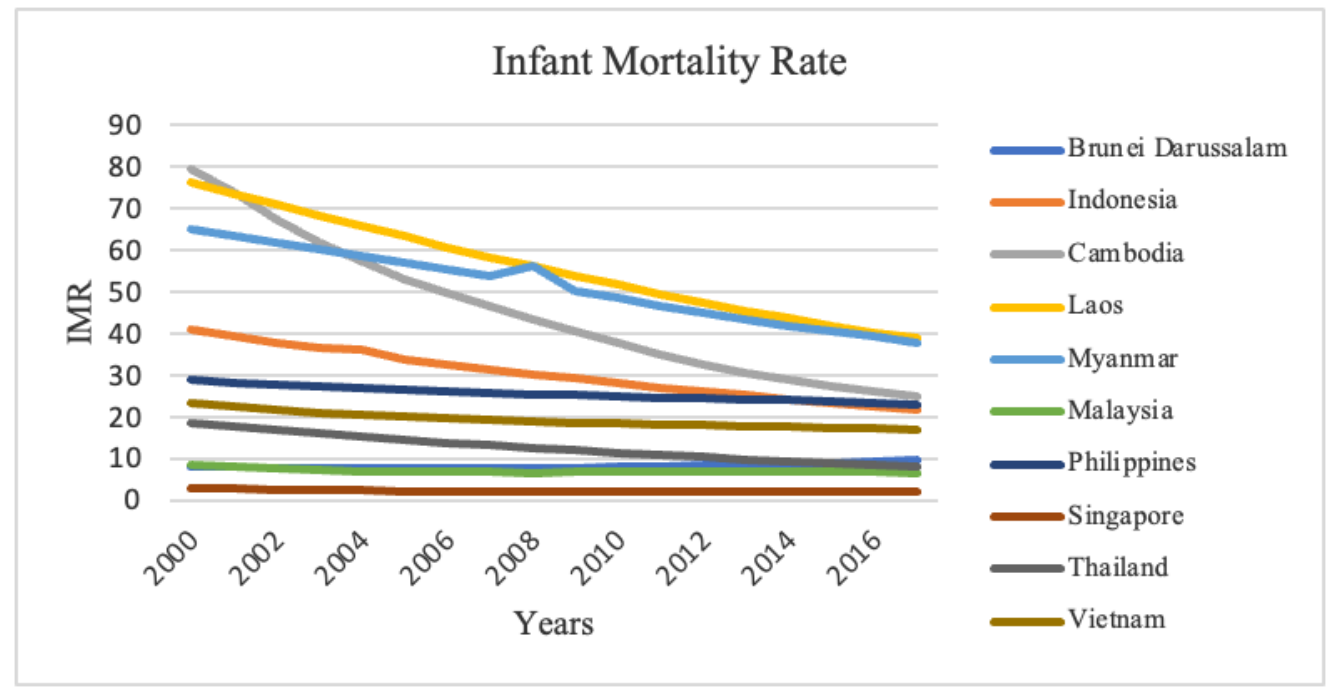

Figure 1 Infant Mortality Rate in ASEAN 2000-2017

Source: World Bank, 2020.

Based on the figure above, the infant mortality rate in ASEAN, in general, has significantly decreased from 2000 to 2017. In aggregate, the highest infant mortality rate was found in Laos, followed closely by Myanmar, while the lowest infant mortality rate was found in Singapore.

ASEAN countries are predominantly developing countries that are rapidly adapting to global changes. The amount of per capita health expenditure in ASEAN shows an increasing trend from 2000-2017, which can be seen in the following figure. Singapore and Brunei Darussalam had the highest health expenditure, followed by Malaysia and Thailand.

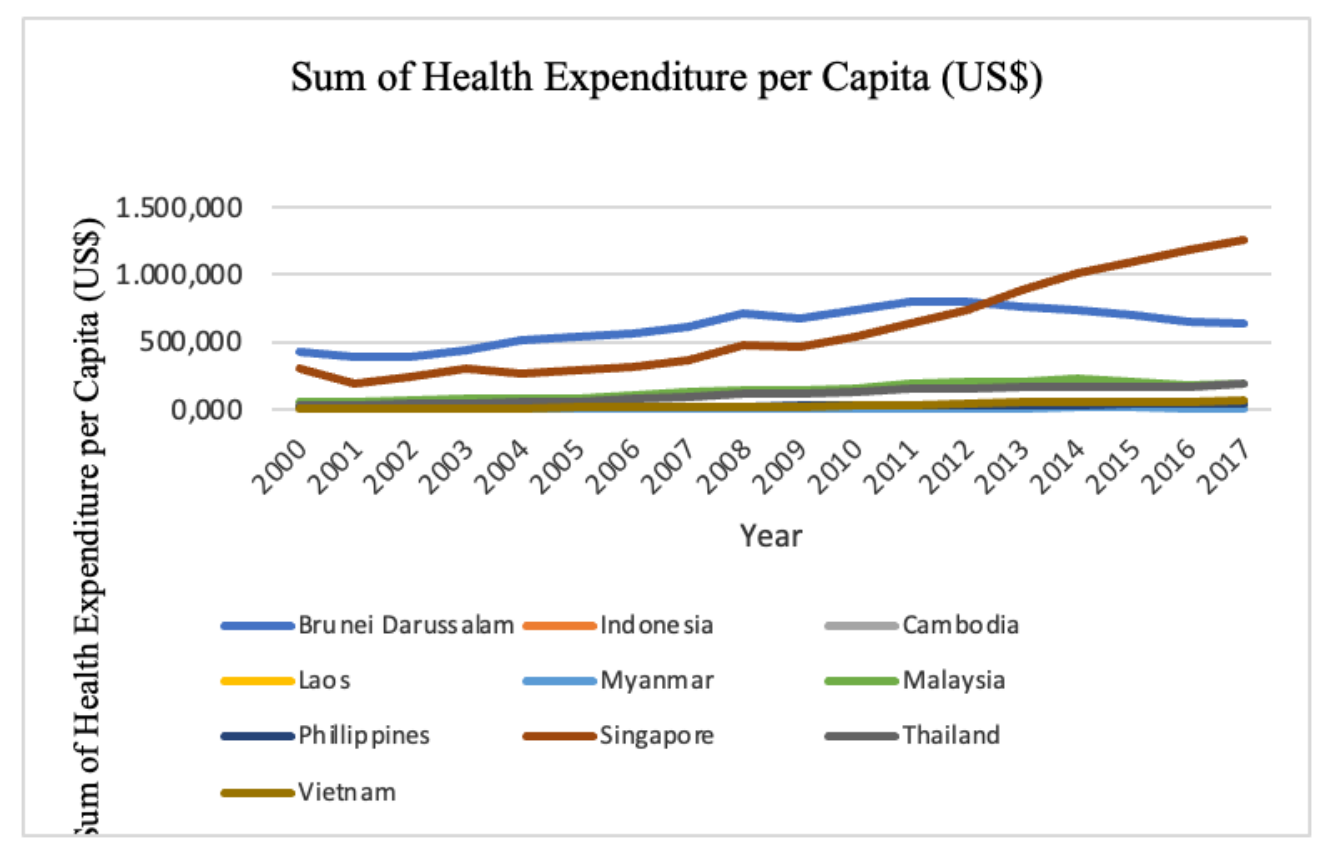

Figure 2 Health Expenditure Per Capita in ASEAN (US Dollar)

Source: World Bank, 2020. 
The infant mortality rate is important for welfare, so the main purpose of this study was to analyze the socioeconomic factors influencing infant mortality rate in ASEAN. Studies analyzing infant mortality rates in ASEAN are still rarely performed. Hence, this study is expected to provide a literature reference related to the infant mortality rate in ASEAN so as to encourage policies advancing the maternal and child health sector.

\section{LITERATURE REVIEW}

Based on the literature, there are two methods for calculating the infant mortality rate: 1) calculation of mortality in newborns, infants, and children under 5 years per 1000 births in a certain time period, or 2) calculation of mortality in infants over 28 days of age, infants aged 1 year, and children 2-4 years old per 1000 living people (Rutstein, 2000). According to Santiago and Tubayan (2016), the infant mortality rate is a key factor of a country's public health status. Improvement of human quality as the main development agent starts from the womb, delivery, childhood education, to adulthood. Maternal health during pregnancy and childbirth can be used as evaluation material to reduce infant mortality. Hanmer, Lensink, and White (2013) stated that development is not only measured by per capita income but must also measure variables such as infant mortality rate, literacy rate, and other social indicators. Ollo (2005) explained two causes of infant mortality: internally, infant mortality is caused by genetic factors, uterine disease, and birth defects, while externally it is caused by accidents.

Maternal fertility rates, nutritional status in pregnancy, smoking, and environmental pollution are thought to have a strong influence on infant mortality rates. The education level of mothers can in the long term affect the welfare of children, involving everything from breastfeeding to parenting style. Women with low education levels (see: Bhatia, et.al, 2018; Dallolio et al., 2012; Klugman, et al, 2019; Ullah, et al, 2011) tend to marry early, have no knowledge of pregnancy and its care, low economic welfare, and have a higher risk of mortality during childbirth.

GDP per capita also plays an important role because the better the standard of living, the better the healthcare (Oloo, 2005). With increase in economic growth, the portion of health expenditure is increased, health programs are expanded, and access to healthcare is becomes easier. Ullah, et al, (2011) pointed out that in developed countries, the government prioritizes maternal and child healthcare, but in poor countries, the government still needs to reduce the infant mortality rate.

Erdogan, Ener, and Arica (2013) described the important role of economic factors on infant mortality rates, with the main factors being equal income distribution and GDP per capita. GDP per capita can have a direct or indirect effect. High-income countries tend to have a higher quality of life in terms of the provision of food, education, and health. In addition, Erdogan, Ener, and Arica (2013) also found empirically, infant mortality rates decreased alongside economic growth in OECD countries, meaning that quality and affordable healthcare is needed to accelerate economic and social development. 
Socio-economic factors also play roles. Rutstein (2000) explained the influence of socioeconomic factors: for example, increasing economic welfare positively improves child health, while social factors such as housing, maternal education, and electricity supply can also affect infant mortality rates. In line with this, Zakir and Wunnava (1999) explained the significant influence of socioeconomic factors, namely maternal fertility rate, female labor force, education level of the mother, and GDP per capita on infant mortality rate in several countries. Shobande (2020) identified the negative influence of energy consumption and pollution on the infant mortality rate in Africa. The infant mortality rate is thus useful for measuring the welfare of the total population over time and the basis for a strategy to improve maternal and child health policies.

Houweling and Kunst (2009) found that the difference in socioeconomic conditions in developed and developing countries is a cause of infant mortality, in addition to health factors such as maternal health, nutrition, and disease. Iram and Butt (2008) identified social factors namely neighborhood, education level of the mother, exclusive breastfeeding, and income had a significant influence on the infant mortality rate in Pakistan. Rezaei, Matin, and Rad (2015) found that the infant mortality rate in Iran was influenced by GDP per capita, the ratio of doctors per 1000 total population, female labor force participation, neighborhood, and education level. Dhrif (2018) found that health expenditure significantly reduced the infant mortality rate in developed countries but was insignificant in poor countries.

Oloo (2005) conducted a study in developing countries and found that the health expenditure per capita and immunization programs had no significant influence on infant mortality rate, but per capita income and maternal fertility had a significant influence on infant mortality rate. Bhatia, et.al (2018) in India found various programs reducing socioeconomic inequality also reduced infant mortality rates. Shobande (2020) identified that energy consumption causing pollution has a negative and significant influence on the infant mortality rate in Africa. Rezaei, Matin, \& Rad (2014) analyzed the influence of GDP per capita, the number of health workers, the female labor force, the total population in villages, maternal fertility rate, and education level on infant mortality rate in Iran. The study found a positive relationship between infant mortality rate, fertility, and population domicile, while the female labor force and GDP per capita were insignificant.

Sarkar, Dhar, and Rouhoma (2018) studied the influencing socioeconomic factors of infant mortality rates in several ASEAN countries and found that education level, delivery assistance by medical personnel, and the population had a significant influence on infant mortality rate. Goldani, et.al (2001) found that social inequality had an influence on the infant mortality rate in Brazil. Hosseinpoor et al. (2005) showed that socioeconomic inequality had an influence on the infant mortality rate between provinces in Iran; this is related to the importance of equitable development policies. Naveed, et al., (2011) with the Vector Error Correction Model (VECM) method aimed to find out the influencing variables of infant mortality rate in Pakistan and found that women's empowerment and income had a negative influence, but the total population had a significant influence on infant mortality rate. Dallolio et al. (2012) found that Gini Index and the unemployment rate had a positive 
influence on infant mortality rate, while the education level of the mother had a negative influence.

ASEAN member countries are faced with the triple challenge of reducing infant mortality, child maternal, and maternal mortality. High infant mortality rates indicate the low quality of maternal and child health services, especially during and after delivery. The government also needs community support to maintain preventive behavior for pregnant women, maintain a healthy living environment, and implement a healthy lifestyle. Therefore, a comprehensive health policy is urgently needed to improve the quality standards of maternal and infant care services in the ASEAN health system.

\section{METHODOLOGY}

The main purpose of this study was to estimate the determining factors of infant mortality rate in ASEAN (Indonesia, Malaysia, Thailand, Singapore, Vietnam, Laos, Cambodia, Brunei Darussalam, the Philippines, and Myanmar). This study used secondary data published by the World Bank, and undertook panel data analysis for the period 20002017 consisting of 10 cross-sections and covering an 18 years' time span. The dependent variable was the infant mortality rate (per 1,000 live births), while the independent variables were health expenditure per capita (US \$), female labor force (\% of the total labor force), maternal fertility rate (births per mother), and GDP per capita (constant LCU). According to Gujarati (2003), panel data is suitable for studying the dynamics of change, makes it easier to understand complex behavior, is good for measuring impacts that simply cannot be seen on cross-section data or time-series data, has more information and variations, can minimize bias generated in the aggregation, and can overcome heterogeneity. The first step in data estimation is looking at the distribution of variables through descriptive statistics and checking the correlation of the independent variables with the infant mortality rate. The data testing panel has three approaches: least square (common effect), fixed effect, and random effect. The common effect method is the simplest method, combining time-series data and cross-section data regardless of the differences in time and individual dimensions. The fixed effect method improves the common effect method by using dummy variables to intercept differences. The random effect method has different parameters between regions and time to be included in the error term, and technically can eliminate heteroscedasticity in the study model.

This study used a development model from previous studies by Hanmer, Lensink, \& White (2003); Oloo (2005); Rezaei, Matin, Rad (2015); and Ullah et al (2011). The study period was chosen based on the economic conditions of ASEAN member countries which in 2000- 2017, which were relatively strong.

$$
\begin{gathered}
I M R_{i t}=\beta_{0}+\beta_{1} H E_{i t}+\beta_{2} W L_{i t}+\beta_{3} F R_{i t}+\beta_{4} G D P / c_{c a p} \\
+e_{i t} \ldots \ldots \ldots \ldots \ldots \ldots \ldots \ldots \ldots \ldots \ldots
\end{gathered}
$$


Equation (1) is Common Effects Model (CEM) estimation, equation (2) is Fixed Effects Model (FEM) estimation, while equation (3) is Random Effects Model (REM). The $\alpha_{0}$ is the intercept while $\beta_{1}, \beta_{2}, \beta_{3}$, and $\beta_{4}$, are the parameters/slope of the model, the ' $\mathrm{i}$ ' is the cross-section of 10 countries in ASEAN while ' $t$ ' is a time series of period 2000-2017. IMR (infant mortality rate), HE (health expenditure per capita), WL (female labor force), FR (maternal fertility rate), and GDP/cap (GDP per capita).

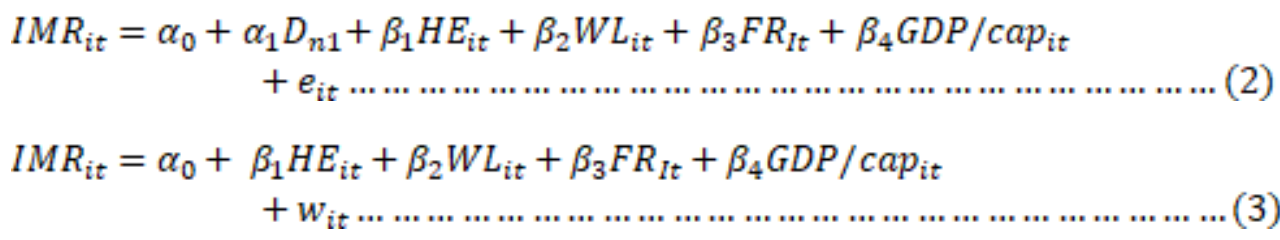

Furthermore, the model was tested with the common effect, fixed effect, and random effect. Then, the Chow test was carried out to test the best fit of the model between the common effect and the fixed effect. The Hausman test was carried out to select the best model between the fixed effect method and the random effect method. The Lagrange Multiplier Test was conducted to select the best model between the random effect model and the common effect model.

\section{RESULTS AND DISCUSSION}

This study used panel data consisting of time series and cross-sections. According to Gujarati (2003), panel data can analyze big data, have a greater degree of freedom, and analyze more efficiently. Panel data analysis can be carried out through three approaches, namely the Pooled Least Squared (PLS)/Common Effect Model (CEM) with fixed coefficients between time and individuals; the fixed-effect model with a constant slope but different intercepts between individuals; and the random effects model with parameter differences between regions or between times are included in the error component. The testing stage was carried out by testing all these methods to find out the best model.

In general, descriptive statistics can be seen in the following table below including the mean, median, minimum value, maximum value, standard deviation, and the number of observations. The data had subtle differences for all countries, except for Singapore. Singapore had the lowest infant mortality rate and highest health expenditure per capita in the ASEAN region. However, in aggregate, there was a significant decrease in infant mortality rate in -between 2000 and 2017. 
Table 1 Descriptive Statistics

\begin{tabular}{lccccc}
\hline & IMR & $\begin{array}{c}\text { Health } \\
\text { Expenditure }\end{array}$ & $\begin{array}{c}\text { Female } \\
\text { Labor Force }\end{array}$ & $\begin{array}{c}\text { Maternal } \\
\text { Fertility Rate }\end{array}$ & GDP/cap \\
\hline Mean & 25.86 & 154.73 & 42.97 & 2.36 & 10299.40 \\
Median & 22.65 & 31.25 & 41.78 & 2.30 & 2459.04 \\
Maximum & 79.50 & 1262.33 & 51.83 & 4.31 & 57378.86 \\
Minimum & 2.20 & 0.39 & 34.69 & 1.15 & 342.14 \\
Std. Dev. & 19.87 & 257.78 & 4.90 & 0.71 & 15459.39 \\
Correlation & 1.00 & -0.89 & 0.48 & 0.79 & -0.89 \\
Observations & 180 & 180 & 180 & 180 & 180 \\
\hline
\end{tabular}

Source: Processed Secondary Data.

With panel data estimates, common effect model and fixed effect model estimates were obtained. To select the best model from the two test models, the Chow test was carried out and found out that the fixed effect model estimate was better and valid than the common effect model. This can be seen from the prob value. Chi-square cross-section $<0.05$, thus, the fixed effect was chosen over the common effect. After that, the random effect model was tested. Based on the Hausman Test to choose between the fixed-effect model and the random effect model, the best estimation model was the random effect model with $\mathrm{H} 0$ or $\mathrm{p}$ value> 0.05. Then, the Lagrange Multiplier Test was carried out to choose the random effect model or the common effect model. Based on the Lagrange Multiplier Test, the random effect model was the best model in estimating data. The p-value was 0,000 at a 0.05 significance level. Thus, based on Lagrange Multiplier Test, H1 was accepted meaning that the best estimation method was the random effect model.

Table 2 Panel Data Estimation Results

\begin{tabular}{lccc}
\hline Variable & Common Effect & Common Effect & Fixed Effects \\
\hline Health Expenditure & $-4.79(0.00)^{* * *}$ & $-4.79(0.00)^{* * *}$ & $-0.92(0.36)$ \\
Female Labor Force & $3.75(0.00)^{* * *}$ & $3.75(0.00)^{* * *}$ & $3.11(0.00)^{* * *}$ \\
Fertility Rate & $11.00(0.00)^{* * *}$ & $11.00(0.00)^{* * *}$ & $3.06(0.00)^{* * *}$ \\
GDP/cap & $-3.92(0.00)^{* * *}$ & $-3.92(0.00)^{* * *}$ & $-5.30(0.00)^{* * *}$ \\
C & $5.77(0.00)^{* * *}$ & $5.77(0.00)^{* * *}$ & $5.49(0.00)^{* * *}$ \\
Adj- R-square: & 0.91 & 0.91 & 0.99 \\
(F-statistics) & 446.18 & 1455.06 & 139.12 \\
Chow Test & & $(0.00)^{* * *}$ & \\
Hausman Test & & & $(0.27)$ \\
LM Test & & & $(0.00)^{* * *}$ \\
Observations & 180 & 180 & 180 \\
\hline
\end{tabular}

Source: Author's estimation

Note: () denotes significance; $* * *, * *$ and $*$ are $1 \%, 5 \%$ and $10 \%$ respectively. 
The results of data estimation with the common effect model showed that health expenditure had a significant and negative influence on infant mortality rates in ASEAN, while female labor force had a significant and positive influence, maternal fertility rate had a significant and positive influence, and GDP per capita had a significant and negative influence.

Based on the random effects model analysis, health expenditure in ASEAN had no influence on infant mortality rates. This occurs because of differences in health expenditure, with the better the welfare of a country, the higher the attention it pays to health, leading to an increase in health expenditure per capita. Brunei Darussalam had the highest health expenditure per capita in ASEAN, Singapore in second, Malaysia in third, and Thailand in fourth, while Vietnam, the Philippines, Myanmar, Laos, Indonesia, and Cambodia had the low health expenditures per capita. This data imbalance shows that the impact of health expenditure was insignificant. Most ASEAN countries have not focused on policies for accessible and affordable health care. This is in line with a study by Dhrif (2018) showing the differences in health expenditure had no influence on infant mortality rates in poor countries but had a positive influence in rich countries. Sarkar, Dhar, and Rouhoma (2018) identified significant differences in developed countries which pay close attention to health, with the provision of health facilities to prevent and reduce the infant mortality rate while developing countries do not have this policy. Goldani, et al. (2001) found that economically weak regions had high infant mortality rates in Brazil. Maternal and child health cases in developing countries are more complex because of the more challenges faced, such as infant mortality, child and maternal malnutrition, stunting, and maternal mortality. Health services are a priority that should be spread throughout all regions to remote areas.

The female labor force has great potential in developing regions such as in ASEAN, by contributing to family income, increasing family purchasing power, and increasing aggregate consumption. Despite this, the female labor force had a significant influence on infant mortality rates. The coefficient of the female labor force was positive, indicating that the more mothers work, the higher the risk of infant mortality. The female labor force had a significant influence with a positive coefficient, meaning that every $1 \%$ increase in the female labor force causes an increase in the infant mortality rate of $0.03 \%$. The maternal fertility rate also had a significant influence with a positive coefficient, meaning that every increase in fertility rate causes an increase in the infant mortality rate. Poerwanto, et al. (2003) found that the infant mortality rate in Indonesia was influenced by the prosperity level and education level of the mother. Low prosperity families tend to have a higher risk, and other factors such as maternal fertility rate, contraception use, birth spacing, and prenatal care also had a significant influence on infant mortality rates. Naveed, et al., (2011) also found that female labor participation and income per capita had a negative correlation on infant mortality rate in the short term. However, in the long run, the female labor force and maternal education had a greater influence than income per capita. This is in contrast to a study by Rezaei, Matin, and $\operatorname{Rad}$ (2015), which found that the female labor force had no influence on the infant mortality rate in Iran. Meanwhile in Poland, the work environment is not conducive and pollution from the industrial sector has an influence on the infant mortality rate (Genowska et al, 2015). 
Based on previous studies, a high infant mortality rate was usually found in economically weak countries. Dhrif (2018) described that this condition is recognized as an important issue because it is closely related to the level of human productivity as a production factor to create economic development and welfare. Productivity starts from infancy and childhood, with good nutrition, education, and environment to improve social and economic conditions. Income is an important variable, a family with a high income can meet the needs of better quality, so as to improve the quality of life and welfare. Based on estimates, GDP per capita had a negative influence on infant mortality rates in ASEAN. GDP per capita had a significant influence on the infant mortality rate, where every $1 \%$ increase in GDP per capita reduces the infant mortality rate by $0.44 \%$. This is in line with studies by Erdogan, Ener, and Arica, (2013) and Naveed, et al. (2011) showing the significant and negative influence of infant mortality rates and GDP per capita. Thus, the increasing prosperity level will be followed by a decrease in the risk of the infant mortality rate. Hosseinpoor, et al. (2005) found that socioeconomic inequality in Iran was the cause of the increased infant mortality rate, where provinces with high economic potential tend to have low infant mortality rates. Rezaei, Matin, and Rad (2015) also found that the insignificant influence of GDP per capita on infant mortality rate in Iran. Household income had no influence on the infant mortality rate in Italy, while the education level of mother had no strong correlation with the infant mortality rate (Dallolio et al, 2012). The risk of infant mortality must thus be viewed from a socioeconomic side in a balanced manner, in order to obtain a realistic policy direction and support weaker economic and social groups.

Modern health services today are more accessible for mothers and children, but this must also be balanced with income equalization so that services are easily accessible by all groups. Continuing social and economic inequality causes high infant mortality rates to be concentrated on poor families. Infant mortality rate censuses are needed for the formulation of development policies, especially in the health and social fields, forecasting population growth, and the possibility of a demographic bonus for sustainable development. Additionally, empowering women has both direct and indirect impacts on awareness of maternal and child health. Therefore, it is necessary to formulate effective health policies to reduce infant mortality rates, because maternal and child welfare determines the health of the next generation.

\section{CONCLUSION}

This study analyzed the socio-economic determinants of infant mortality rates in ASEAN member countries as an indicator of adequate human capital. Socio-economic variables such as female labor force, health expenditure, maternal fertility rate, and GDP per capita have previously been analyzed in other studies and were found to have a significant influence on infant mortality rates in various countries. High GDP per capita was also found to reduce infant mortality due to higher health spending on maternal and child health.

This study estimated the influence of socioeconomic factors on infant mortality rate in ASEAN,. The social variable was the maternal fertility rate, while the economic variables 
were health expenditure, female labor force, and GDP per capita. Data estimation used static panel data model with balanced panels. Based on the estimation results, the best result was found in the random effect model. This study found that there was a significant influence of the female labor force and maternal fertility rate on infant mortality rates in ASEAN countries. Meanwhile, health expenditure per capita had no significant influence on infant mortality rate, but GDP per capita had a significant and negative influence.

Thus, the recommendations of this study are: 1) strategies are needed to provide accessible and affordable health facilities for all groups, 2) increase awareness of women's empowerment through educational programs on maternal and child health, 3) improve social conditions in society, and income equalization to improve citizen welfare. This study was limited by excluding other socio-economic variables which may influence infant mortality rates in ASEAN.

\section{ABOUT THE AUTHORS}

This Vita Kartika Sari is a lecturer at the Department of Economics Development Sebelas Maret University. She graduated from Bachelor of Economics Development, Sebelas Maret University in 2010, and graduated her Master of Science in Economics, Gadjah Mada University in 2012. Her research interests include institutional economics, public economics, and monetary economics.

Dr. Dwi Prasetyani, S.E., M.Si. is a lecturer at the Department of Economics Development, Faculty of Economics and Business, Sebelas Maret University. She graduated from Bachelor of Economics and Development Studies, Sebelas Maret University in 1999, then continued her Masters in Development Economics, Gadjah Mada University in 2001, and continued her Doctoral Program in Economics, Brawijaya University in 2018. Her research interests include Institutional Economics and Public Policy, Industrial Economics, Business Society/Environment, Entrepreneurship, MSMEs, Small and Medium Industries, Gender Study, and Women Empowerment.

\section{REFERENCES}

Arik, Hulya \& Arik, Murat. (2009). Is It Economic Growth or Socioeconomic Development? A Crosssectional Analysis of the Determinants of Infant Mortality. The Journal of Developing Areas, Spring, 2009, Vol. 42, No. 2 pp. 31-55.

Bhatia, M, et al. (2018). Mind the Gap: Temporal Trends in Inequalities in Infant and Child Mortality in India (1992-2016). Population Health 5 (2018) 201-209.

Chaudhuri, S. \& Mandal, B. (2020). Predictive Behaviour of Maternal Health Inputs and Child Mortality in West Bengal - An Analysis Based on NFHS-3. Heliyon 6 (2020) e03941. 
Dallolio, Laura, et.al. (2012). Socio-Economic Factors Associated with Infant Mortality in Italy: An Ecological Study. International Journal for Equity in Health 2012, 11:45.

Dhrif, Abdelhafidh. (2018). Health-Care Expenditures, Economic Growth and Infant Mortality: Evidence from Developed and Developing Countries. CEPAL Review $N^{\circ}$ 125 August 2018.

Erdogan, Engin., Ener, Meliha., and Arica, Feyza. (2013). The Strategic Role of Infant Mortality in the Process of Economic Growth: An Application for High Income OECD Countries. Procedia - Social and Behavioral Sciences 99 (2013) $19-25$.

Genowska, et al. (2015). Environmental and Socio-Economic Determinants ff Infant Mortality in Poldan: An Ecological Study Environmental Health (2015) 14:61.

Goldani, Marcelo Zubaran, et al., (2001). Infant Mortality Rates According to Socioeconomic Status in A Brazilian city. Rev Saúde Pública 2001;35(3):256-61.

Gomez, Eva O. Arceo., Hanna, Rema., Oliva, Paulina. (2012). Does The Effect of Pollution on Infant Mortality Differ Between Developing and Developed Countries? Evidence From Mexico City. NBER Working Paper Series Working Paper 18349.

Gujarati, Damodar N. (2003). Basic Econometrics. McGraw Hill.

Hanmer, Lucia., Lensink, Robert and White, Howard. (2003). Infant and Child Mortality in Developing Countries: Analysing the Data for Robust Determinants. Journal of Development Studies · October 2003.

Houweling, Tanja A. J. \& Kunst, Anton E. (2009). Socio-Economic Inequalities in Childhood Mortality in Low- Dan Middle-Income Countries: A Review of The International Evidence. British Medical Bulletin 2010; 93: 7-26.

Hosseinpoor, Ahmad Reza, et al. (2005). Socioeconomic Inequality in Infant Mortality in Iran and Across Its Provinces. Bulletin of the World Health Organization November 2005, 83 (11).

Iram, Uzma and Butt, Muhammad S. (2008). Socioeconomic Determinants of Child Mortality in Pakistan Evidence from Sequential Probit Model. International Journal of Social Economics Vol. 35 No. 1/2, 2008 pp. 63-76.

Lamichhane, et al. (2017). Factors Associated with Infant Mortality in Nepal: A Comparative Analysis of Nepal Demographic and Health Surveys (NDHS) 2006 dan 2011. BMC Public Health (2017) 17:53.

Naveed, Tanveer Ahmed. (2011). Socio-economic Determinants of Infant Mortality in Pakistan. Interdisciplinary Journal of Contemporary Research in Business. December 2011 Vol 3, No 8.

Oloo, James A. (2005). Child Mortality in Developing Countries: Challenges and Policy Options. Eastern Africa Social Science Research Review· June 2005. 
Poerwanto S, Stevenson M, Klerk N. (2003). Infant Mortality and Family Welfare: Policy Implications for Indonesia. J Epidemiol Community Health. 2003, 57:493-8.

Rezaei, Satar., Matin, Behzad Karami., Rad, Enayatollah Homaie. (2015). Socioeconomic Determinants of Infant Mortality in Iranian Children: A Longitudinal Econometrics Analysis. Int J Pediatr, Vol.3, N.1-1, Serial No.13, January 2015.

Rosicova, Katarina. (2011). Regional Socioeconomic Indicators and Ethnicity as Predictors of Regional Infant Mortality Rate in Slovakia. Int J Public Health (2011) 56:523-531.

Rutstein, Shea O. (2000). Factors Associated with Trends in Infant and Child Mortality in Developing Countries During The 1990s. Bulletin of the World Health Organization, 2000, 78: 1256-1270.

Santiago, Rollen D. \& Tubayan, Elijah Joseph C. (2016). The Relationship of Health-Related Factors to Labor Productivity of the ASEAN-5. Rev. Integr. Bus. Econ. Res. Vol 5(4).

Sarkar, Sabrina Maria., Dhar, Bablu Kumar., and Rouhoma, Hatem Mohammed. (2018). A Cross Sectional Analysis of Socio-economic Determinants on Infant Mortality in South Asian Region. International Journal of Business Society, 2 (2), 1-6.

Shobande, O.A. (2020). The Effects of Energy Use on Infant Mortality Rates in Africa. Environmental and Sustainability Indicators 5 (2020) 100015.

The Global Health Observatory. (2020). World Health Organization. http://who.int.

Ullah, Sami et al. (2011). Socio-economic Determinants of Infant Mortality in Pakistan. Interdisciplinary Journal of Contemporary Research In Business, December 2011 Vol 3, No 8 .

World Development Indicators. (2020). The Worldbank. http://worldbank.org.

Zakir, M., Wunnava, P. (1999), Factors Affecting Infant Mortality Rates: Evidence from Cross-Sectional Data. Applied Economics Letters, 6: 271-273. 